\title{
An exploratory water quality analysis of the Hawkesbury-Nepean River catchment
}

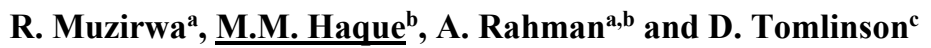 \\ ${ }^{a}$ School of Computing, Engineering and Mathematics, University of Western Sydney \\ ${ }^{b}$ Institute for Infrastructure Engineering, University of Western Sydney \\ ${ }^{c}$ WaterNSW \\ Email:m.haque@uws.edu.au
}

\begin{abstract}
Water is a vital resource for the survival of all living organisms. This important resource should be protected by ensuring that anthropogenic activities do not impact adversely the sustainability of water resources. Therefore, monitoring and assessment of rivers is required to inform planning regulations in order to safeguard community and stakeholders' requirements in terms of water quality. Due to the high rate of population growth, development, increased agricultural use of land and industrialization, water quality in urban and peri-urban rivers has deteriorated over the last three decades.

This paper explores the water quality of the Hawkesbury-Nepean River (HNR) in New South Wales (NSW), Australia. The relevance of this lies in the fact that there have been audits in Australia that have found dramatic deterioration in some rivers' health due to its surrounding land-use activities. In the past, there have also been incidents in the Sydney region where the water quality deteriorated to a critical state triggering public dissatisfaction and subsequent changes in water management authorities.

This paper examines water quality at four different monitoring stations along the HNR using about sixteen years of data (2000 to 2015). This covers six water quality parameters, which are algae, E. coli, total nitrogen, total phosphorus, conductivity and turbidity. The results indicate that stations which are located near the urban areas have higher pollution levels; however, further study is needed to confirm this initial finding.
\end{abstract}

Keywords: Hawkesbury-Nepean River, water quality, land use, pollutant, urban runoff 


\section{INTRODUCTION}

The Australian and New Zealand Environment and Conservation Council (ANZECC) is responsible for setting standard trigger values for water quality parameters to ensure that water quality is in good condition in Australian and New Zealand rivers. They have identified that unsustainable land use practices in the past within Australia have led to the degradation of water resources and have warranted the adoption of water management practice to reduce/prevent further pollution of Australian Rivers (ANZECC, 2000). These conditions indicate that both protection and improvement of water resources is needed to achieve future improvement of the river water quality. As availability of water resources is decreasing in many parts of the world due to rapid urbanization, rise in population, increase water demand and climate change (Haque et al., 2014a, 2014b, 2015), it is important to maintain water quality in the rivers to obtain necessary supply of water to the cities. Therefore, it is essential to build a good understanding of the sources of pollutants, their mobilization and delivery into the river systems (Bende-Michl et al., 2013).

Australia is known to be one of the driest continents on earth and is prone to droughts and highly variable rainfall. It is therefore crucial that Australian water resources are preserved and enhanced in terms of both quantity and quality. Due to the high rate of population growth, urban development and industrialization, there has been an increased focus and scrutiny on water quality in urban and peri-urban rivers over the last 23 decades. This is owing to the increased public awareness that water is vital for the survival of all living organisms and should be protected by ensuring that anthropogenic activities do not impact badly the sustainability of water resources. It is therefore essential to have continuous monitoring and assessment of river health in order to safeguard community and stakeholder satisfaction with water quality.

An audit by the National Land and Water Resources in Australia found that a large number of Australian river basins had nutrient concentration levels above the acceptable standards (Bowmer, 2011). Dramatic deterioration in some rivers' health has also been linked to surrounding land-use (Bowmer, 2011). In 1998, Sydney faced a critical water quality incident where the water quality within the Hawkesbury-Nepean River (HNR) deteriorated to precarious conditions (Gardner, 2003; Kuruppu and Rahman, 2013). This led to public dissatisfaction and subsequent changes in water management policies and procedures in the Sydney region.

A river can be affected by point source, diffuse and non-point source pollutants. Point source pollution in a river is often the result of industrial and urban activities, such as sewage discharge and mine wastes (Smith, 1998). Diffuse source pollutants are the result of activities such as land clearing and cultivation, urban and agricultural development. The runoff from these lands can increase the suspended solids, turbidity, eutrophication, salinity and chemical/microbiological contamination level in urban and peri-urban rivers (ARMCAN, 2000).

The HNR system is one of the most important river systems in Australia as it provides water to over 4.5 million people in Sydney, the largest city in Australia (Kuruppu and Rahman, 2015). This paper examines water quality at four monitoring stations along the HNR. Four priority pollutants identified by Water NSW in their 2014-2015 Healthy Catchments Program are pathogens, phosphorus, nitrogen and suspended solids (WaterNSW, 2014); three of these pollutants are considered in this study.

\section{MATERIALS AND METHOD}

The catchment of the HNR has an area of $22,000 \mathrm{~km}^{2}$, covering the north and west of the Sydney Basin. About $3,700 \mathrm{~km}^{2}$ of this area is known as 'special areas', which cover areas of mostly unspoilt bushland surrounding reservoirs that provide drinking water to Sydney. These special areas are vital to protect Sydney's drinking water as they help filtering out undesirable nutrients and other substances from water before the runoff enters into the reservoir system. Figure 1 presents the HNR system near the study area, close to Penrith local government area (LGA), NSW.

With the knowledge that the quality of water in a river changes as the river goes downstream (Bek and Robinson, 1991), the collection stations chosen for this study provide a combination of upstream and downstream stations. These stations are therefore expected to have different hydrological conditions and nutrient concentrations, hence allowing a comprehensive analysis of the impact of land use on the water quality of the HNR.

The selected water quality monitoring stations (from upstream to downstream) are (i) Pheasants Nest Weir (N42); (ii) Nepean River at Penrith Weir (N57) and (iv) Nepean River downstream of the confluence of Warragamba Dam (N64); and (iv) Cordeaux River feed into Pheasants Nest Weir (N86). These selected stations fall near the LGAs, which has undergone massive urbanization over the last decade. Urbanization is known to reduce agricultural lands with impervious surfaces, whilst forests become more disaggregated (Liu 
and Weng, 2013). This has been the case for Penrith LGA, which is presently characterised by reduced agricultural land and increased impermeable surfaces, such as roof tops, roads and paved paths.

The focus of this paper is to assess the state of water quality at the HNR near Penrith LGA. The data for this study are obtained from WaterNSW covering sixteen year (2000 to 2015). This data period includes both dry and wet spells, i.e. variety of hydrologic conditions are captured by these data. In this assessment, a total of six water quality parameters are considered, which are algae, E. Coli, total phosphorus, total nitrogen, turbidity and conductivity. Boxplots and time series plots are used to interpret these water quality data.



Figure 1. Water quality collection stations along the Hawkesbury Nepean River (WaterNSW, 2015). 


\section{RESULTS AND DISCUSSION}

Algae levels at three monitoring stations along the HNR are presented in Figure 2. It can be seen that the data collection between the period 2003 and 2012 was not regular as there are many missing data points. Of importance, Station N42 had a spike in algae levels in mid-2012, and another spike in mid-2013. Station N42 also shows a spike in algae levels in mid-2014. The boxplot of algae levels shows that station N42 and N64 have median values (the meeting value of red and yellow color in Figure 2) close to each other, though N42 clearly has the highest algae level. The inter-quartile range (IQR), which is difference between the $75^{\text {th }}$ and $25^{\text {th }}$ percentile, is found to be very high for N42 and N57, indicating a high variability in the algae level at those stations. The algae level at Station N86 was not examined due to data unavailability.

Figure 3 shows the E. Coli levels in Stations N42, N57, N64 and N86, and provides a comparison among the stations with respect to the recommended ANZECC level of E. Coli. N57 has the highest median E. Coli among the four stations, whilst N64 and N86 have similar median values with relatively smaller values compared with N57. Station N57 has a wider IQR showing large variability in the data. This is clearly shown in the time series plot, which shows spikes in E. Coli level at N57 in 2003, 2007 and 2011. These are also the periods when the algae levels have been above the recommended ANZECC levels. Between 2007 and 2014, there is a higher incidence of all stations having E. Coli levels going above ANZECC guidelines.

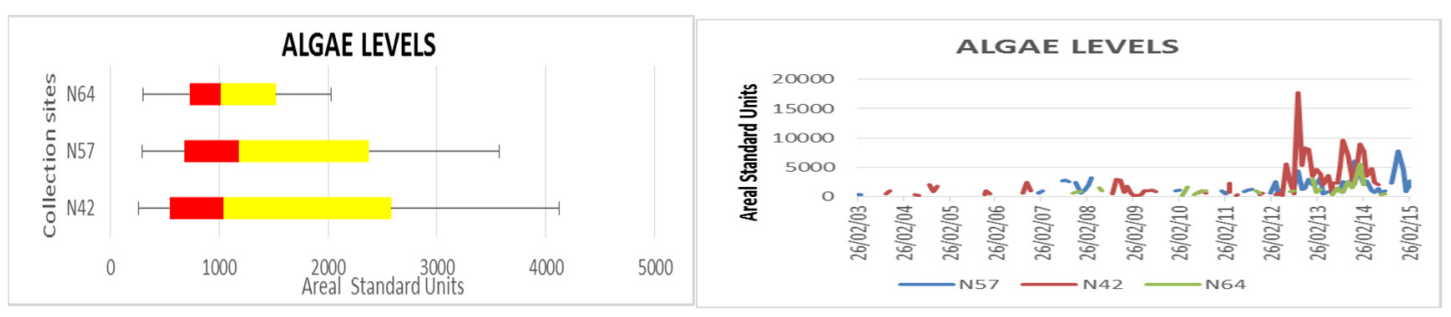

Figure 2. Algae levels at Stations N42, N57 and N64.

Figure 4 shows the total phosphorus (TP) levels at the four stations. The time series plot shows that TP levels are significantly above the recommended ANZECC levels for Stations N57 and N42 between the years 1990 and 2000, which is followed by a significant drop till the current date. Station N64 has some spikes in TP levels in 2008, 2012 and 2014. The boxplot of TP also shows that N64 has a wider IQR demonstrating a large variability in its TP data. N42 also has a wider IQR and the highest median value.

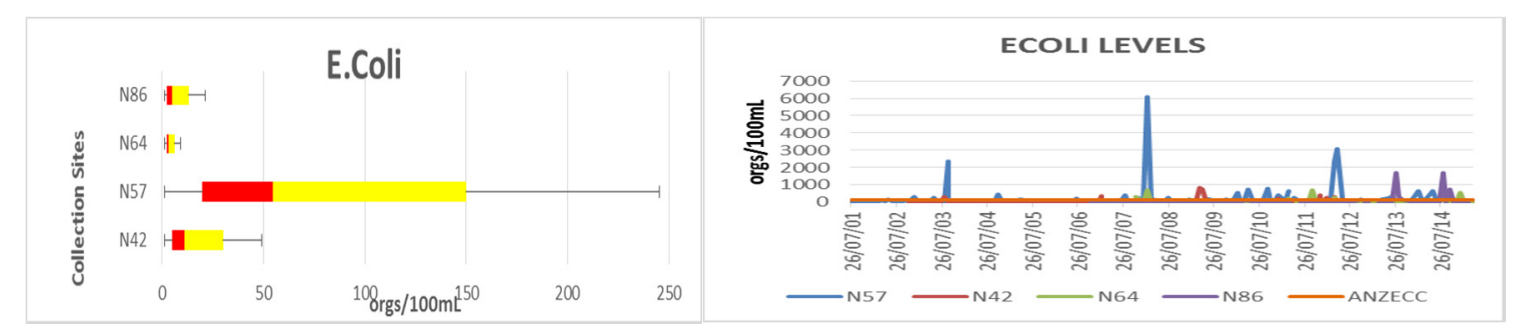

Figure 3. E. Coli levels at Stations N42, N57, N64 and N86.
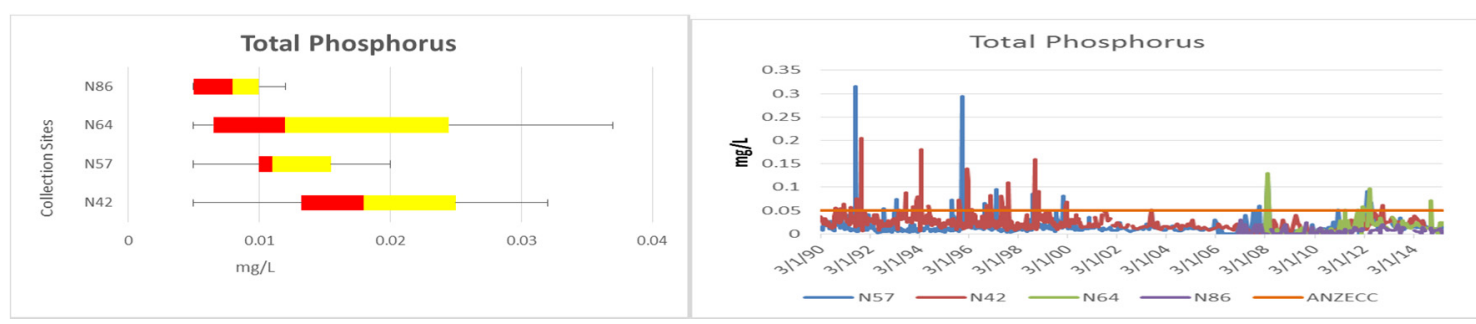

Figure 4. Total phosphorus levels at Stations N42, N57, N64 and N86.

Figure 5 shows the total nitrogen (TN) levels at the four stations where it can be seen that between 1999 and 2010, all the stations (except N86) have TN levels above the ANZECC guidelines. However, between 2011 and 2014, TN level falls within the recommended levels indicating a recent improvement. The boxplot of TN shows that N64 and N42 have the widest IQR, hence the biggest variability in the TN levels. N86 has the lowest median value and N42 has the highest median value. 


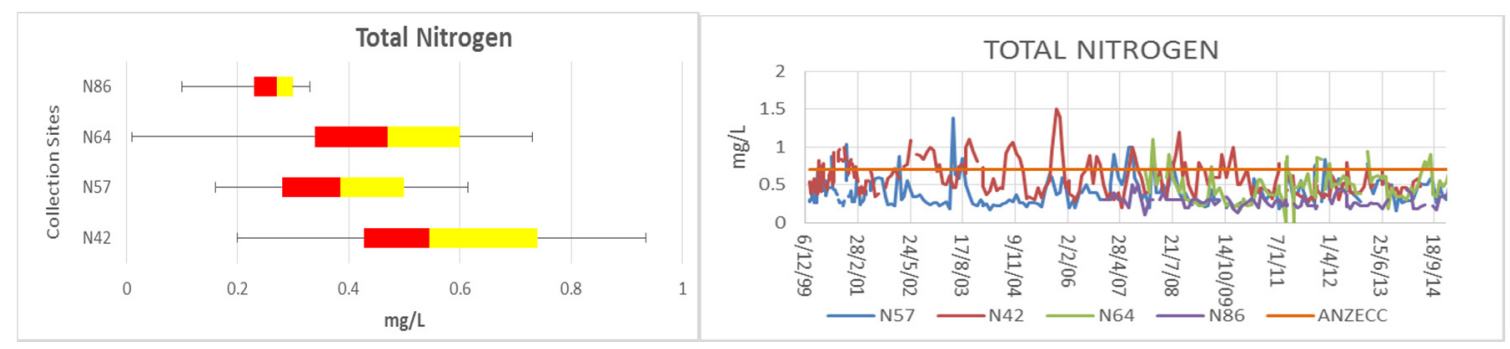

Figure 5. Total nitrogen levels at Stations N42, N57, N64 and N86.

Figure 6 shows the conductivity levels at the four stations between the period 2006 and 2014. The median values for N64 and N57 are very similar. N57 has the widest IQR. Conductivity levels for N86 are very stable with minimum fluctuation.

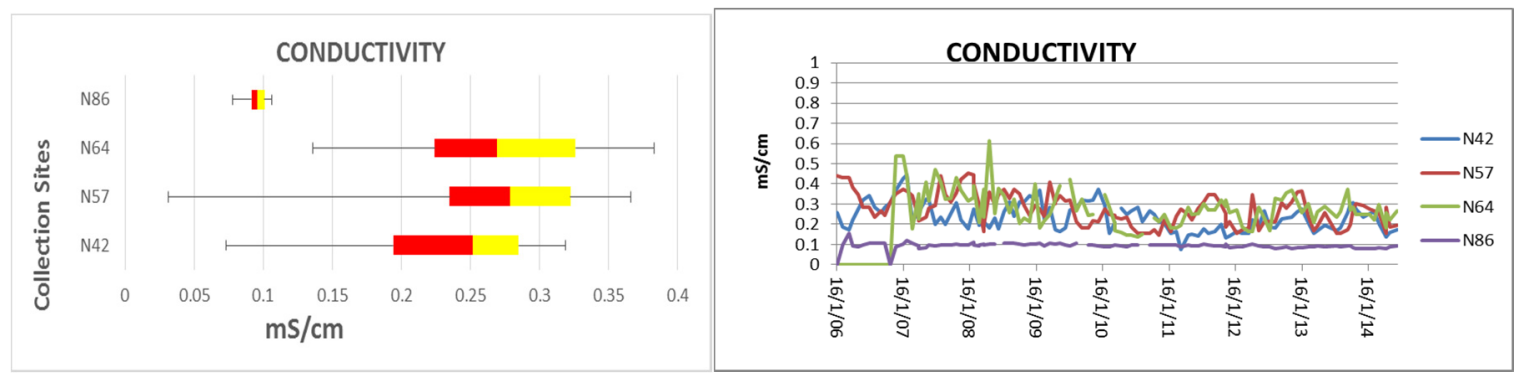

Figure 6. Conductivity levels at Stations N42, N57, N64 and N86.

Figure 7 shows the turbidity levels of all the four stations where it can be seen that N86 has the highest turbidity values, and N57 and N42 have very similar median values. However, between 2010 and mid-2013, N42 and N57 show significant rise in their turbidity levels.

From the above results, it can be seen that Stations N42 and N57 represent the most polluted parts of the HNR with respect to TN, TP, E. Coli and algae levels. They have the highest number of exceedances of the ANZECC guidelines and also they have the highest variability in pollutant levels. Figure 1 indicates that these stations are in close proximity to large urban development areas and have a motorway adjacent to the river. Urban runoff has the potential to dramatically alter the water quality of receiving water and hence is a significant contributor to the pollution of surface waters internationally (Valtanen et al., 2014). Station N86 has the lowest pollutant levels, which lies furthest from urban areas and is less affected by land use changes. These results indicate that the HNR has been notably impacted by urban and industrial developments along its urban corridor near the Penrith LGA. However, further study is needed to confirm this initial finding.

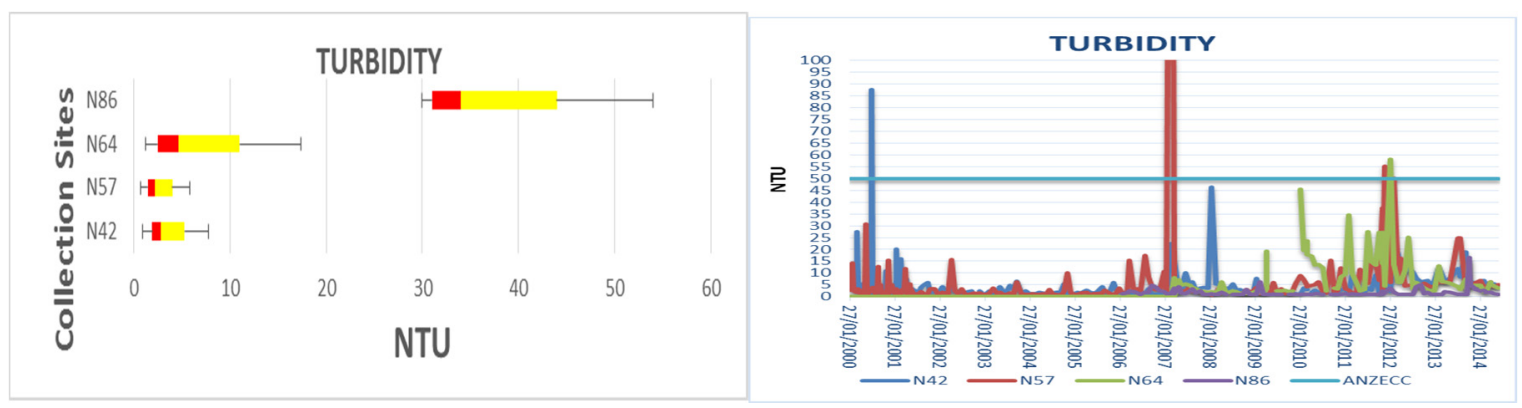

Figure 7. Turbidity levels at Stations N42, N57, N64 and N86.

\section{CONCLUSION}

This study examines water quality in the Hawkesbury Nepean River (HNR) system using water quality data at four different monitoring stations covering a period of sixteen years (2000 to 2015). A total of six water quality parameters are considered in this study, which are algae, E. Coli, total nitrogen, total phosphorus, conductivity and turbidity. The results indicate that Stations N42 and N57 are the most polluted among the four stations examined here. Station N86 has the lowest pollution level, which is located furthest from urban area and hence less affected by urbanisation. These results indicate that the HNR has been notably impacted by urban development; however, further study is needed to confirm this initial finding. 
Muzirwa et al., An exploratory water quality analysis of the Hawkesbury-Nepean River catchment

\section{ACKNOWLEDGEMENTS}

We acknowledge WaterNSW for providing the water quality data for this study.

\section{REFERENCES}

Australian and New Zealand Environment and Conservation Council (2000). National Water Quality Management Strategy: Rural Land Uses and Water Quality. ANZECC, Australia.

Bende-Michl, U., Verburg, K., and Cresswell, H.P. (2013). High-frequency nutrient monitoring to infer seasonal patterns in catchment source availability, mobilisation and delivery. Environmental Monitoring Assessment, 185, 9191-9219.

Bowmer, K.H. (2011). Water resource protection in Australia: Links between land use and river health with a focus on stubble farming systems. Journal of Hydrology, 403, 176-185.

Egodawatta, P., and Goonetilleke, A. (2008). Modelling Pollutant Build-up and Wash-off in Urban Road and Roof Surfaces. Water Down Under, Adelaide Australia.

Griffith, M., and Tate, P. (2014). Hawkesbury Nepean River and South Creek Model: A review of a new tool to inform management decisions in the Hawkesbury Nepean Catchment. Water, 51-57.

Haque, M.M., Hagare, D., Rahman, A., and Kibria, G. (2014a). Quantification of water savings due to drought restrictions in water demand forecasting models. Journal of Water Resources Planning and Management, 140(11), 04014035.

Haque, M.M., Rahman, A., Hagare, D. and Kibria, G. (2014b). Probabilistic water demand forecasting using projected climatic data for Blue Mountains Water Supply System in Australia. Water Resources Management, 28(7), 1959-1971.

Haque, M.M., Rahman, A., Hagare, D., Kibria, G., and Karim, F. (2015). Estimation of catchment yield and associated uncertainties due to climate change in a mountainous catchment in Australia. Hydrological Processes, doi: 10.1002/hyp.10492.

Kuruppu, U., and Rahman, A. (2013). An exploratory analysis of water quality in the Nepean River, Australia, 35th IAHR World Congress. September 8 to 13, 2013 Chengdu, China, 1-6.

Kuruppu, U., and Rahman, A. (2015). Trends in water quality data in the Hawkesbury-Nepean River System, Australia. Journal of Water and Climate Change, doi:10.2166/wcc.2015.120.

Niemczynowicz, J. (1999). Urban hydrology and water management - present and future challenges. Urban Water 1, 1-14.

Nouh, M., and Al-Noman, N. (2009). Regression models for the prediction of water quality in the stormwater of urban arid catchments. Canadian Journal of Civil Engineering, 36, 331-344.

Smith, D.I. (1998). Water in Australia: Resources and Management. Oxford University Press, Melbourne.

Valtanen, M., Sillanpaa, N., and Setala, H. (2014). The Effects of urbanization on runoff pollutant concentrations, loadings, and their seasonal patterns under cold climate. Water Air and Soil Pollution, 225(1977), 1-16.

Warner, R.F. (2006). Impacts of environmental degradation on rivers, with some examples from the Hawkesbury-Nepean system. Australian Geographer, 22:1.

Warner, R.F. (2014). Environmental flows in two highly regulated rivers: the Hawkesbury Nepean in Australia and the Durance in France. Water and Environment Journal, 28, 365-380.

WaterNSW (2014). Healthy catchments program, 2014-2015. Viewed at 1/05/2015, http://www.sca.nsw.gov.au/ data/assets/pdf file/0008/47249/Healthy-Catchments-Program-20142015.pdf

Weatherhead, E.K., and Howden, N.J.K. (2009). The relationship between land use and surface water resources in the UK. Land Use Policy, 265, S423-250. 